VET BRIEF

ZOOS' PRINT JOURNAL 20(2): 1786

\section{ISOLATION OF SALMONELLA TYPHIMURIUM FROM A PIGEON SQUAB (COLUMBIA LIVIA)}

\author{
M.A. Malik ${ }^{1}$, T.R. Mohanty ${ }^{1}$, N.K. Singh ${ }^{2}$ and \\ S.K. Kotwal ${ }^{2}$
}

${ }^{1}$ Division of Veterinary Pathology, FVSc \& A.H.R.S. Pura, SKUASTJammu, Jammu \& Kashmir 181102, India

${ }^{2}$ Division of Veterinary Surgery \& Radiology, FVSc \& A.H.R.S.

Pura, SKUAST-Jammu, Jammu \& Kashmir 181102, India

Salmonella typhimurium, frequently called the mouse typhoid bacillus, causes severe outbreaks of salmonellosis in all kinds of animals (Hagan \& Bruner, 1961). Severe losses due to this organism are seen in young domestic birds. In pigeon lofts $S$. typhimurium causes heavy losses in squabs. The squabs either die soon after hatching or develop swollen wing joints which renders them unable to fly. Infection by this organism is manifested by enteritis, diarrhoea and septicaemia in fatal cases. Another important symptom is the neuromotor defects caused by encephalitis or infection of the inner ear. $S$. typhimurium has got zoonotic significance since it causes gastroenteritis in man on consumption of contaminated food and water. The signs of disease are fever, nausea, vomiting and abdominal cramps with profuse diarrhoea which may persist up to one week. There may be septicaemia and even death in older patients.

A pigeon squab off-fed dull depressed, flightless with ruffled feathers and passing greenish droppings was found abandoned by the loft at R.S. Pura, Jammu. On further examination wing joints were apparently swollen. The bird was administered Biotrim (Ranbaxy Laboratories Limited) liquid (orally) but it did not respond and died after two days. Postmortem examinations was conducted and visceral organs revealed haemorrhages. Heart blood and liver were collected for bacterial isolation using aseptic techniques.

In this study the symptoms exhibited by the bird were similar to those reported by Fowler (1986) that S. typhimurium to be the cause of swollen wing joints, arthritis and sudden death in pigeons. S. typhimurium can also be transmitted through the egg into developing embryos. In the present case the said pigeon squab might have contracted the infection through trans-ovarian route. The organism was isolated from the liver of the bird and identified on the basis of morphological and biochemical characteristics (Edwards \& Ewing, 1972). $S$. typhimurium could not be isolated from the heart blood, which may be due to the low recovery rate of salmonella from this organ. Hui and Das (2001) isolated salmonella from different organs of ducks and reported the highest percentage of organism from liver followed by intestine, heart, gall bladder and spleen.

The drug sensitivity of the isolate was carried out by modified Kirby-Baur method (Carter, 1973) and the organism was found to be sensitive to chloremphenicol, norf1oxacin, ciprofloxacin and cotrimaxazole. The organism was resistant to gentamicin, cephalexin, cephataxim, streptomycin and oxytetracycline. Shivhare et al. (2000) found S. typhimurium to be sensitive to norfloxacin and ciprofloxacin. Threlfall et al. (1983) reported varying degree of resistance in S. typhimurim to gentamicin, tetracyclines, ampicillin and sulphonomides. Since $S$. typhimurim is of public health concern and there is development of antibiotic resistant strains of this organism, a judicious use of antibiotics based on their sensitivity pattern should be practiced.

\section{REFERENCES}

Carter, G.R. (1973). Diagnostic Procedures in Veterinary Microbiology ( $2^{\text {nd }}$ edition). Charles C. Thomas, Springfield, USA.

Edwards, P.R. and W.H. Ewing (1972). Identification of Enterobacteriaceae ( $3^{\text {rd }}$ edition). Burgess Publishing Co. Minneapolis, Minnesota.

Fowler, M.E. (1986). Zoo and Wild Animal Medicine ( $2^{\text {nd }}$ edition). W.B. Saunders Company, London, 441pp.

Hagan, W.A. and D.W. Bruner (1961). The infectious diseases of domestic animals (4 ${ }^{\text {th }}$ edition). Billiere, Tindall and Cox, London, 222pp. Hui, A.K. and R. Das (2001). Studies on isolation, serotyping and antibiotic sensitivity of salmonellae isolated from ducks. Indian Veterinary Journal 78: 1058-1059.

Shivhare, S., R. Sharda, A.G. Reddy, R.K. Sharma and V. Sharma (2000). Antibiotic sensitivity of Salmonella typhimurium isolates from domestic poultry. Indian Veterinary Journal 77: 998-999.

Threlfall, E.J., B. Rowe, J.L. Ferguson and L.R. Ward (1983). Veterinary Records 113:627.

\section{ACKnOWLedgements}

The facilities rendered by the Division of Veterinary Pathology, FVSc \& A.H., R.S. Pura are greatly acknowledged. 